\title{
BMJ Open Low back pain in emergency ambulance workers in tertiary hospitals in China and its risk factors among ambulance nurses: a cross-sectional study
}

\author{
Qiong Zhang, ${ }^{1}$ Hongyun Dong, ${ }^{\circledR 2}$ Chunji Zhu, ${ }^{1}$ Guangzeng Liu ${ }^{1}$
}

To cite: Zhang Q, Dong $\mathrm{H}$, Zhu $\mathrm{C}$, et al. Low back pain in emergency ambulance workers in tertiary hospitals in China and its risk factors among ambulance nurses: a crosssectional study. BMJ Open 2019;9:e029264. doi:10.1136/ bmjopen-2019-029264

- Prepublication history for this paper is available online. To view these files, please visit the journal online (http://dx.doi. org/10.1136bmjopen-2019029264).

Received 19 January 2019 Revised 19 August 2019 Accepted 30 August 2019
Check for updates

(C) Author(s) (or their employer(s)) 2019. Re-use permitted under CC BY-NC. No commercial re-use. See rights and permissions. Published by BMJ.

${ }^{1}$ Shouguang People‘s Hospital, Shouguang, Weifang, , China ${ }^{2}$ Shouguang People's Hospital, Shouguang, Weifang, , China

Correspondence to Dr Hongyun Dong; ayouwang@163.com

\section{ABSTRACT}

Objective Low back pain (LBP) could cause serious consequences and has been shown to be prevalent among emergency ambulance workers. Studies on the prevalence of and risk factors for LBP among emergency ambulance workers are scarce in China. The study aimed to determine the prevalence of LBP among ambulance workers, including doctors, nurses and drivers, and to explore the risk factors for ambulance nurses' chronic LBP (lasting for at least 3 months).

Design Cross-sectional study.

Setting Emergency ambulance systems from 38 tertiary hospitals in Shandong, China were selected by random cluster sampling.

Participants A total of 1560 ambulance workers completed the study.

Outcome measures A paper-based questionnaire that included the Nordic Musculoskeletal Questionnaire, which evaluated LBP, the Dutch Musculoskeletal Questionnaire, which assessed ergonomic factors, and the Job Content Questionnaire, which assessed stress, was used. Multivariate logistic regression analysis was conducted to quantify the association of potential risk factors with chronic LBP among ambulance nurses.

Results The 1 year prevalence of LBP lasting for at least 24 hours, 7 days and 3 months was $86.1 \%, 50.6 \%$ and $21.1 \%$, respectively, among 498 ambulance nurses; $70.5 \%, 36.4 \%$ and $15.8 \%$ among 519 doctors; and $57.5 \%, 23.8 \%$ and $12.3 \%$ among 543 drivers. The factors contributing to chronic LBP among ambulance nurses were the frequent bending of the trunk, heavy or awkward lifting, shift work, low job satisfaction, high psychological fatigue, high psychological job demand, low job control, low supervisor support, older age, female sex and obesity. Conclusions LBP was more prevalent among ambulance nurses than among ambulance doctors and drivers. Many factors, especially psychosocial and ergonomic factors, contributed to ambulance nurses' chronic LBP. Comprehensive measures might be needed to control LBP.

\section{INTRODUCTION}

Emergency ambulance service, as an essential part of the healthcare system, provides prehospital medical emergency service for patients, including carrying, moving and transporting patients to an emergency centre

\section{Strengths and limitations of this study}

- This is the first large-scale study on the prevalence of low back pain (LBP) among emergency ambulance workers and risk factors for ambulance nurses' LBP in China.

- Various factors, including individual, psychosocial, ergonomic and organisational factors, were collected and analysed in the study.

- The cross-sectional design and subjective measures of the study limited the establishment of causal directions.

- Those subjects having left ambulance position due to LBP were not included in the study, which might underestimate the prevalence of LBP and the extent of its risk factors.

and treating them in the ambulance, such as performing cardiopulmonary resuscitation. Ambulance workers have been reported to experience more musculoskeletal disorders than the general workforce. ${ }^{1-4}$ In Denmark, data from a nationwide study showed that a substantially high proportion $(42 \%)$ of 1689 ambulance personnel reported musculoskeletal pain, which was significantly higher than corresponding reports from the core workforce of 14175 individuals $(29 \%) .^{5}$ In Australia, ambulance officers and paramedics had the highest rates for musculoskeletal injury compared with other healthcare workers in the 2003-2012 time period. ${ }^{6}$ Worldwide, attention has been paid to the musculoskeletal disorders of ambulance workers over the last decade because of serious consequences, such as reduced quality of life, loss of working days, occupational disability and the need to change and/ or leave a profession. ${ }^{7}$ Due to musculoskeletal disorders, especially low back pain (LBP), ambulance workers have been reported to suffer from a higher standardised early retirement than other healthcare providers and the 
general workforce. ${ }^{18}$ In mainland China, scarce attention has been paid to emergency ambulance workers, and no study thus far has explored the prevalence of LBP among ambulance workers and their risk factors.

Studies $^{9-11}$ have reported that many factors could contribute to LBP, including individual, psychosocial, physical and organisational work factors. Psychosocial factors, including low job support, job dissatisfaction and occupational stress, and individual factors, such as high BMI and being female, could contribute to musculoskeletal disorders of the back region, as revealed by a systematic review with strong evidence. ${ }^{12}$ However, regarding the LBP among a special occupational group, the above factors do not have the same effects. Psychosocial factors at work, such as stress, fatigue and job dissatisfaction, have been demonstrated to largely contribute to the development of LBP in a follow-up study of 4500 Iranian industrial workers. ${ }^{13}$ Emergency ambulance workers, especially nurses, are faced with demanding nursing skills, rapid pace of work, episodes of violence, threats, increased risks of contracting infectious diseases and increasing demands on medical competence. ${ }^{14-18}$ Therefore, ambulance nurses may also suffer from LBP resulting from psychosocial factors, and this effect is not well known. Besides, in mainland China, during the process of transporting patients to emergency centre, most often, ambulance nurse needs to do the lifting, sometimes with the help of ambulance doctor while ambulance driver is only responsible for driving the ambulance vehicle, which might contribute to prevalence variance of LBP among ambulance workers. The current study aimed to evaluate the prevalence of LBP among ambulance workers in different work positions and to determine and quantify the association between influencing factors, including individual, physical and psychosocial factors, and chronic LBP (lasting for at least 3 months) among ambulance nurses.

\section{METHODS}

A cross-sectional survey was implemented from September to November 2018. The study was approved by the Ethics Committee of Shouguang People's Hospital. Informed consent was obtained before the participants were invited to participate.

\section{Participants}

Given the prevalence of LBP, the number of independent variables in the logistic regression and the response rate, 38 hospitals were selected first by random cluster sampling from among all the tertiary hospitals (182 tertiary-level hospitals in total) in Shandong, China. Then, of the selected 38 hospitals, all the emergency ambulance workers who had at least 1 year of work experience in this job were invited to participate in collaboration with the the management departments and the directors of emergency departments. The exclusion criteria were as follows: part-time workers or workers who had experienced trauma, injury or serious diseases. A total of $1560 \mathrm{ambu}-$ lance workers (498 nurses, 519 doctors and 543 drivers) completed our questionnaire, and the response rate of the study was $90.8 \%$.

\section{Questionnaire}

A self-administered questionnaire that included the Standardised Nordic Musculoskeletal Questionnaire, ${ }^{19}$ the Dutch Musculoskeletal Questionnaire ${ }^{20}$ and the Job Content Questionnaire, ${ }^{21}$ was revised after a pilot study. The paper-based questionnaire consisted of four sections. Section 1 addresses demographic information, including age, sex, height, weight, marital status, smoking, alcohol consumption, educational level, marital status, the presence of the children at home and exercise.

Section 2 was a modified version of the Standardised Nordic Musculoskeletal Questionnaire. The participants were asked whether they had suffered from pain or discomfort in the low back region lasting for at least 24 hours, 7 days and 3 months in the preceding 12 months. If a participant reported LBP lasting for at least 3 months in the past 12 months, he or she was considered to have chronic LBP. ${ }^{22}$ The Chinese version of the Nordic questionnaire has been widely used, validated and contextualised by previous national studies according to a cross-cultural understanding of the Chinese population. ${ }^{23-25}$

Section 3 addresses work information and ergonomic factors mainly derived from Dutch Musculoskeletal Questionnaire ${ }^{20}$ which has been systematically translated into Chinese $^{23}$ and validated. ${ }^{24}$ Ergonomic factors, which were directly selected from the Chinese version Dutch Musculoskeletal Questionnaire, were measured using a dichotomous scale (yes/no), and the assessment of risk factors was qualitative in this study. ${ }^{20} 23$ Participants were asked whether they were often exposed to the ergonomic risk factors during their work. Work information included work position (doctor, nurse or driver), shift work or day work, work experience and employment status (permanent vs temporary/contract).

Section 4 addresses psychosocial factors, including job satisfaction (high, medium, low), self-perceived health status (very good, generally good, generally bad, very bad), psychological fatigue (low, medium, high) and occupational stress assessed by the Job Content Questionnaire (JCQ), which has been widely used in different groups of numerous studies and has shown good reliability and validity in the Chinese working population. ${ }^{21}$ In our study, 22 items of the original 49-item JCQ were applied and consisted of three dimensions: psychological job demand (five items); job control, including skill discretion (six items), decision-making authority (three items); and workplace social support, including supervisor social support (four items) and coworker social support (four items). Each item was scored on a four-point Likert scale from 'strongly disagree' to 'strongly agree', with higher scores indicating higher psychological job demand, job control and workplace social support. In this study, Cronbach's $\alpha$ coefficients for psychological job demand, job 
Table 1 Characteristics of emergency ambulance workers in tertiary hospitals

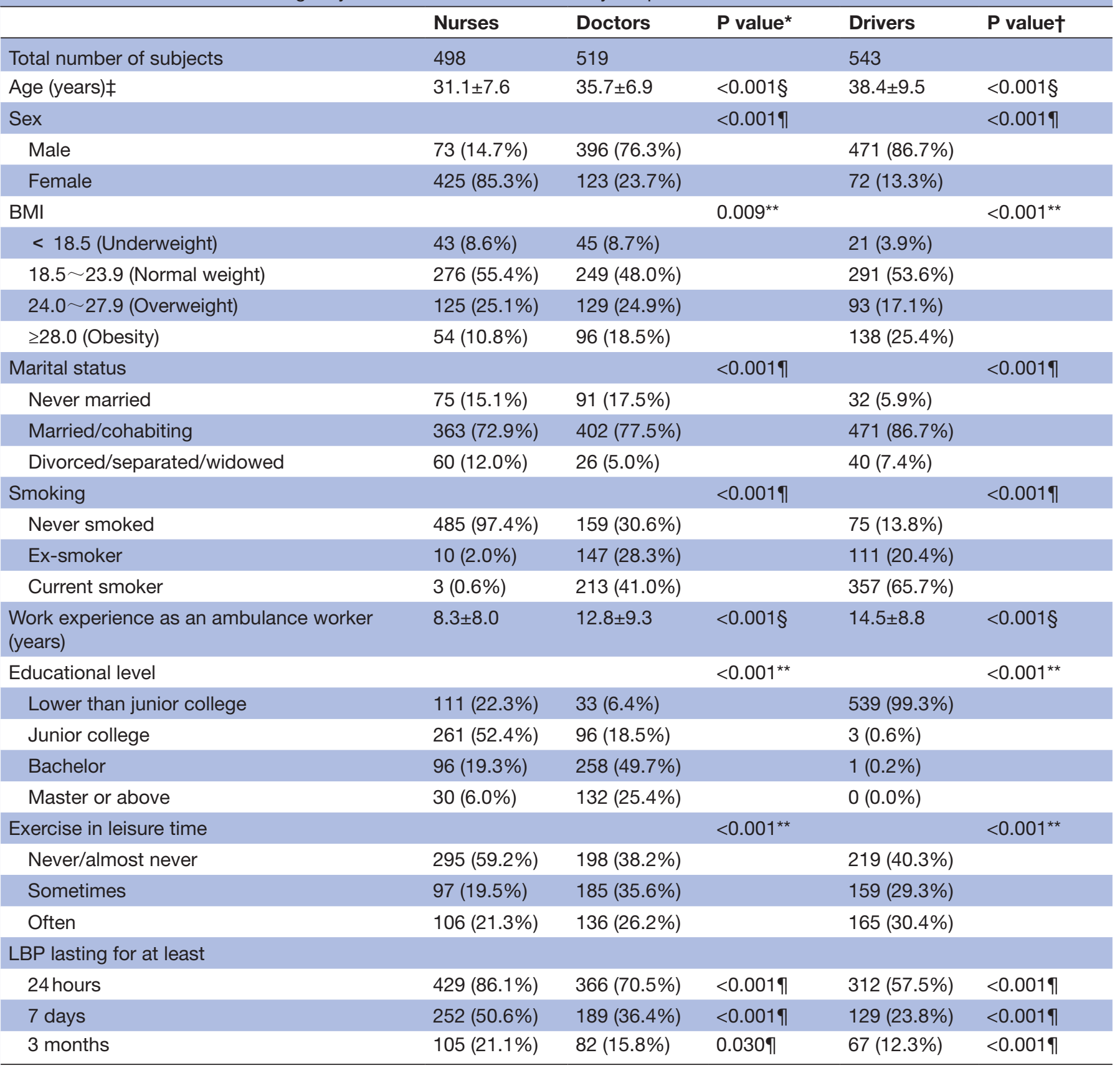

${ }^{*} P$ value between ambulance nurses and doctors.

$\dagger P$ value between ambulance nurses and drivers.

$\ddagger$ Mean \pm standard deviation.

$\S$ t;t-test, .

I $\chi^{2}$ test.

${ }^{\star \star}$ Rank-sum test.

control and workplace social support were $0.79,0.87$ and 0.90 , respectively. The validity of the Chinese version JCQ has been confirmed in previous Chinese studies. ${ }^{21}$

\section{Data analysis}

The SPSS, V.18.0, was used to perform statistical analysis. A single-factor $\chi^{2}$ test, independent t-test or rank-sum test was used to examine the differences between different groups of participants. The association of physical, psychosocial, organisational and individual factors with chronic LBP (lasting for at least 3 months) was first examined with univariate analysis. The significant factors selected at the $\mathrm{p}$ value of 0.25 in the univariate analysis were then entered into multivariate logistic regression analysis. ORs and 95\% CI were calculated to evaluate the effect of risk factors on chronic LBP. To avoid an inaccurate and unstable logistic regression model, the significant variable 'work experience' 
Table 2 Univariate analysis of individual and ergonomic factors with chronic LBP among ambulance nurses

\begin{tabular}{|c|c|c|c|}
\hline Factors & Chronic LBP & Non-chronic-LBP & $P$ value \\
\hline Number of subjects & 105 & 393 & \\
\hline Age (years) ${ }^{*}$ & $36.5 \pm 7.7$ & $29.7 \pm 6.7$ & $<0.001 \dagger$ \\
\hline Male & 8 & 65 & \\
\hline Female & 97 & 328 & \\
\hline$<18.5$ (Underweight) & 4 & 39 & \\
\hline $18.5 \sim 23.9$ (Normal weight) & 45 & 231 & \\
\hline $24.0 \sim 27.9$ (Overweight) & 29 & 96 & \\
\hline$\geq 28.0$ (Obesity) & 27 & 27 & \\
\hline Whether takes shift work? & & & $<0.001 \ddagger$ \\
\hline Work experience as an ambulance worker (years) ${ }^{*}$ & $13.8 \pm 8.7$ & $6.8 \pm 7.2$ & $<0.001 \dagger$ \\
\hline Employment status & & & $0.014 \ddagger$ \\
\hline Permanent & 39 & 199 & \\
\hline Temporary/contract & 66 & 194 & \\
\hline \multicolumn{4}{|l|}{ Ergonomic factors } \\
\hline Walking for long periods of time (Yes/No) & $54 / 51$ & $154 / 239$ & $0.024 \ddagger$ \\
\hline Frequent bending of the trunk (Yes/No) & $66 / 39$ & $93 / 300$ & $<0.001 \ddagger$ \\
\hline Heavy or awkward lifting (Yes/No) & $75 / 30$ & $112 / 281$ & $<0.001 \ddagger^{*}$ \\
\hline Bending or twisting the neck (Yes/No) & $39 / 66$ & $97 / 296$ & $0.011 \ddagger^{*}$ \\
\hline
\end{tabular}

${ }^{*}$ Mean \pm standard deviation.

tt;t-test.

$\mp \chi^{2}$ test.

$\S$ Rank-sum test.

in the univariate analysis was removed, and 'age' was kept for the multivariate analysis, as it showed collinearity in relationships $(\rho>0.6)$ diagnosed by Spearman correlation matrix. The statistics for variable entry and removal were set at $p<0.05$ and $p>0.1$, respectively, in the multivariate analysis. And the multivariate logistic regression analysis was also conducted separately in ambulance doctors and drivers, in addition to ambulance nurses. A 0.05 statistical significance level was set for all tests.

\section{Patient and public involvement}

No patients or members of the public were involved in the design or implementation of the study. The results of the study were disseminated to the health authorities and the selected 38 hospitals.

\section{RESULTS}

All 1560 participants (498 ambulance nurses, 519 doctors and 543 drivers) were included in the study, and with respect to the questionnaires that were not fully completed, the participants were contacted again and completed them later. Approximately 158 individuals $(65$ ambulance nurses, 49 doctors and 44 drivers) failed to participate in the survey due to long leaves for vacation, sick leave, maternity leave and personal affairs.

The mean age of the 498 ambulance nurses was $31.1 \pm 7.6$ years, which was significantly younger than ambulance doctors $(35.7 \pm 6.9)$ and drivers (38.4 \pm 9.5$)$. Most of the ambulance nurses were women, while most of the ambulance doctors and drivers were men. Most nurses never smoked. Ambulance nurses had significantly less work experience as an ambulance worker (8.3 \pm 8.0 years) than did ambulance doctors (12.8 \pm 9.3 years) and drivers (14.5 \pm 8.8 years). Ambulance nurses had an educational level that was significantly higher than that of drivers and lower than that of doctors, and the rank-sum test is shown in table 1 . Nurses exercised less than doctors and drivers did in their leisure time (table 1 ). 
Table 3 Univariate analysis of psychosocial factors with chronic LBP among ambulance nurses

\begin{tabular}{|c|c|c|c|}
\hline Psychosocial factors & $\begin{array}{l}\text { Chronic } \\
\text { LBP }\end{array}$ & $\begin{array}{l}\text { Non- } \\
\text { chronic } \\
\text { LBP }\end{array}$ & $P$ value \\
\hline Number of subjects & 105 & 393 & \\
\hline \multicolumn{4}{|l|}{ Occupational stress } \\
\hline $\begin{array}{l}\text { Psychological job } \\
\text { demand* }^{*}\end{array}$ & $14.5 \pm 4.1$ & $11.1 \pm 3.2$ & $<0.001 \dagger$ \\
\hline $\begin{array}{l}\text { Decision-making } \\
\text { authority* }\end{array}$ & $5.8 \pm 3.8$ & $8.1 \pm 2.5$ & $<0.001 \dagger$ \\
\hline Skill discretion* & $11.7 \pm 5.3$ & $16.2 \pm 4.6$ & $<0.001 \dagger$ \\
\hline $\begin{array}{l}\text { Supervisor social } \\
\text { support* }^{*}\end{array}$ & $6.8 \pm 3.2$ & $9.8 \pm 2.2$ & $<0.001 \dagger$ \\
\hline $\begin{array}{l}\text { Coworker social } \\
\text { support* }^{*}\end{array}$ & $8.7 \pm 3.8$ & $10.3 \pm 2.6$ & $<0.001 \dagger$ \\
\hline $\begin{array}{l}\text { Health status self- } \\
\text { perceived }\end{array}$ & & & $0.043 \ddagger$ \\
\hline Very good & 19 & 89 & \\
\hline Generally good & 25 & 109 & \\
\hline Generally bad & 29 & 117 & \\
\hline Very bad & 32 & 78 & \\
\hline Psychological fatigue & & & $0.004 \ddagger$ \\
\hline Low & 27 & 127 & \\
\hline Medium & 45 & 207 & \\
\hline High & 33 & 59 & \\
\hline Job satisfaction & & & $0.025 \ddagger$ \\
\hline High & 42 & 187 & \\
\hline Medium & 33 & 144 & \\
\hline Low & 30 & 62 & \\
\hline
\end{tabular}

*mean \pm standard deviation.

†t-test.

‡Rank-sum test.

The 12-month prevalence of LBP lasting for at least 24 hours, 7 days and 3 months was $86.1 \%, 50.6 \%$ and $21.1 \%$, respectively, among ambulance nurses; $70.5 \%$, $36.4 \%$ and $15.8 \%$ among doctors; and $57.5 \%, 23.8 \%$ and $12.3 \%$ among drivers. For more details, see table 1.

Ambulance nurses who were older in age, were female, had higher BMI, performed shift work and had worked longer as an ambulance worker and in temporary/ contract employment seemed to suffer from chronic LBP more. Regarding ergonomic factors, walking for long periods of time, the frequent bending of the trunk, heavy or awkward lifting, bending or twisting the neck and maintaining shoulder abduction for long periods of time were all statistically associated with chronic LBP. For more details, see table 2.

Regarding the psychosocial factors, scores on psychological job demand were positively associated with chronic LBP, while scores on skill discretion, decision-making authority, workplace supervisor support and coworker support were negatively associated with chronic LBP among ambulance nurses. Univariate analysis also showed that self-perceived health status, job satisfaction and psychological fatigue were all associated with chronic LBP. For more details, see table 3.

Multivariate logistic regression analysis revealed that age, sex, BMI, work shift, frequent bending of the trunk, heavy or awkward lifting, psychological fatigue, job satisfaction, psychological job demand, skill discretion, decision-making authority and workplace supervisor support were independently associated with chronic LBP among ambulance nurses. For more details, see table 4.

Multivariate logistic regression analysis also revealed that age, sex, BMI, frequent bending of the trunk and psychological job demand were associated with chronic LBP among ambulance doctors and that age, BMI, sitting for long periods of time and psychological fatigue were associated with chronic LBP among ambulance drivers. For more details, see table 5 .

\section{DISCUSSION}

In this study, we found that the 12-month prevalence of LBP lasting for at least 24 hours, 7 days, and 3 months was $86.1 \%, 50.6 \%$ and $21.1 \%$, respectively, among ambulance nurses; $70.5 \%, 36.4 \%$ and $15.8 \%$, respectively, among ambulance doctors; and $57.5 \%, 23.8 \%$ and $12.3 \%$, respectively, among ambulance drivers. The risk factors that were found for the ambulance nurses' chronic LBP were ergonomic factors (frequent bending of the trunk, heavy or awkward lifting), occupational stress (high psychological job demand, low job control and low workplace supervisor support), high psychological fatigue, low job satisfaction, shift work and individual factors (age, sex, obesity).

In our study, the prevalence of LBP lasting for at least 24 hours, 7 days and 3 months among ambulance nurses was statistically higher than that among ambulance doctors and drivers. Regarding LBP lasting for at least 24 hours, the prevalence was higher among ambulance nurses than the general nursing personnel in Greece $(75 \%),{ }^{26}$ Nepal $(67 \%),{ }^{27}$ Chinese Taiwan $(66.0 \%)^{28}$ and other countries. ${ }^{26} 2930$ Regarding chronic LBP (lasting for at least 3 months), the prevalence among ambulance nurses was higher than nursing personnel in the Netherlands $(12 \%),{ }^{26}$ Greece $(11 \%)^{26}$ and Taiwan $(8.6 \%) .{ }^{28}$ Although measurement variance, cultural differences and differences in the perception of terminology may exist among the above mentioned studies, more attention should be paid to the ambulance nurses' LBP. As reported by the COST B13 Working Group on Guidelines for the Management of Acute Low Back Pain in Primary Care, over $70 \%$ of people in industrialised countries suffer from short-term or minor LBP at some point in their lives, ${ }^{22}{ }^{31}$ and most acute LBP is a self-limiting symptom with a recovery rate of $90 \%$ within 6 weeks. ${ }^{22} 32$ Serious or chronic LBP was caused mainly by work and other factors. 
Table 4 Multivariate logistic regression analysis of chronic LBP risk factors among ambulance nurses

\begin{tabular}{|c|c|c|c|c|}
\hline Factors & B & SE & $P$ value & OR $(95 \% \mathrm{CI})$ \\
\hline Age (years) & 0.912 & 0.453 & 0.023 & 2.489 (1.024 to 6.049$)$ \\
\hline Sex $(1=$ female, $0=$ male $)$ & 0.891 & 0.381 & 0.017 & $2.438(1.155$ to 5.144$)$ \\
\hline $18.5 \sim 23.9$ (Normal weight) & & & & Reference \\
\hline$<18.5$ (Underweight) & -0.641 & 0.546 & 0.513 & $0.527(0.181$ to 1.536$)$ \\
\hline$\geq 28.0$ (Obesity) & 1.638 & 0.313 & $<0.001$ & 5.145 (2.786 to 9.502$)$ \\
\hline Whether takes shift work ( $1=$ shift work, $0=$ day work) & 1.005 & 0.223 & $<0.001$ & 2.732 (1.765 to 4.229$)$ \\
\hline \multicolumn{5}{|l|}{ Ergonomic factors } \\
\hline Frequent bending of the trunk ( $1=y e s, 0=$ no) & 1.701 & 0.232 & $<0.001$ & 5.479 (3.477 to 8.634$)$ \\
\hline Heavy or awkward lifting ( $1=y e s, 0=$ no) & 1.838 & 0.242 & $<0.001$ & 6.284 (3.911 to 10.098$)$ \\
\hline Low & & & & Reference \\
\hline Medium & 0.021 & 0.267 & 0.214 & 1.021 (0.605 to 1.723$)$ \\
\hline High & 0.968 & 0.296 & $<0.001$ & 2.633 (1.474 to 4.703$)$ \\
\hline \multicolumn{5}{|l|}{ Job satisfaction } \\
\hline High & & & & Reference \\
\hline Medium & 0.031 & 0.262 & 0.154 & 1.031 (0.617 to 1.724$)$ \\
\hline Low & 0.768 & 0.279 & $<0.001$ & 2.155 (1.248 to 3.724$)$ \\
\hline \multicolumn{5}{|l|}{ Occupational stress } \\
\hline Psychological job demand & 1.031 & 0.414 & $<0.001$ & 2.804 (1.246 to 6.312$)$ \\
\hline
\end{tabular}

Therefore, we analysed the risk factors of chronic LBP other than short-term LBP.

We found that ergonomic factors (the frequent bending of the trunk, heavy or awkward lifting and sitting for long periods of time) were associated with chronic LBP. In line with our study, a cross-sectional study ${ }^{28}$ in Taiwan found that certain manual patient-transfer tasks played important roles in severe LBP (such as care seeking, intense pain and sick leave). Patient handling, as one of the main tasks of nurses, could generate a severe biomechanical load on spinal parts of the body and could impose compressive and shear forces on nurses' low spine. ${ }^{33}$ In contrast to the ergonomic factors for chronic LBP among ambulance doctors (frequent bending of the trunk) and drivers (sitting for long periods of time) and in contrast to the findings of a cohort study ${ }^{34}$ in Norway that showed that prolonged standing and awkward lifting were important factors of the ergonomic factors for LBP, our study found the frequent bending of the trunk and heavy or awkward lifting contributed to chronic LBP, which again confirmed the above findings among ambulance nurses. Musculoskeletal loads and injuries resulting from patient-handling tasks need to be reduced and could be reduced by efficient and cost-effective ergonomic intervention measures, including sharing LBP knowledge, transferring equipment, lifting teams and training in safe patient-transfer techniques reported by previous studies. $^{35}$ Therefore, to prevent chronic LBP among ambulance nurses, ergonomic intervention measures need to be taken.

Psychosocial factors are perceived feelings of the work environment that could bring about psychological fatigue, job dissatisfaction and occupational stress. ${ }^{36}$ First, our study found that psychological fatigue and job satisfaction were all associated with chronic LBP, consistent with the findings of other studies ${ }^{37}$ that showed that employees dissatisfied with their work were more prone to complain of back pain. High psychological fatigue could not only negatively affect one's physical and mental work performance but also increase the possibility of medical errors and worker injuries. ${ }^{39-42}$ Second, our study found that occupational stressors, including high psychological job demand, low job control and low supervisor support, were independently associated with chronic LBP, consistent with the findings of other studies. ${ }^{4} 44$ A cohort study ${ }^{34}$ of the general working population in 
Table 5 Multivariate logistic regression analysis of chronic LBP risk factors among ambulance doctors and among ambulance drivers

\begin{tabular}{|c|c|c|c|c|}
\hline Factors & B & SE & $P$ value & OR $(95 \% \mathrm{Cl})$ \\
\hline \multicolumn{5}{|l|}{ For doctors' chronic LBP } \\
\hline Age (years) & 1.031 & 0.448 & $<0.001$ & $2.804(1.165$ to 6.747$)$ \\
\hline \multicolumn{5}{|l|}{ BMI } \\
\hline $18.5 \sim 23.9$ (Normal weight) & & & & Reference \\
\hline $24.0 \sim 27.9$ (Overweight) & 0.556 & 0.309 & 0.141 & 1.744 (0.952 to 3.195$)$ \\
\hline$\geq 28.0$ (Obesity) & 1.571 & 0.322 & $<0.001$ & 4.811 (2.560 to 9.044$)$ \\
\hline \multicolumn{5}{|l|}{ Ergonomic factors } \\
\hline Frequent bending of the trunk ( $1=y e s, 0=$ no) & 1.313 & 0.352 & $<0.001$ & 3.717 (1.865 to 7.411$)$ \\
\hline \multicolumn{5}{|l|}{ Psychosocial factors } \\
\hline \multicolumn{5}{|l|}{ For drivers' chronic LBP } \\
\hline Age (years) & 1.115 & 0.501 & 0.004 & 3.050 (1.142 to 8.141$)$ \\
\hline \multicolumn{5}{|l|}{ BMI } \\
\hline $18.5 \sim 23.9$ (Normal weight) & & & & Reference \\
\hline < 18.5 (Underweight) & -0.722 & 0.473 & 0.643 & $0.486(0.192$ to 1.228$)$ \\
\hline $24.0 \sim 27.9$ (Overweight) & 0.948 & 0.305 & $<0.001$ & 2.581 (1.419 to 4.692$)$ \\
\hline$\geq 28.0$ (Obesity) & 1.804 & 0.354 & $<0.001$ & 6.074 (3.035 to 12.156$)$ \\
\hline \multicolumn{5}{|l|}{ Ergonomic factors } \\
\hline Sitting for long periods of time $(1=y e s, 0=$ no $)$ & 1.936 & 0.315 & $<0.001$ & $6.931(3.738$ to 12.851$)$ \\
\hline
\end{tabular}

Norway showed that psychosocial factors such as high psychological job demands and low job control were reported as the most consistent and important predictors of LBP, in addition to ergonomic factors. In a prospective study, ${ }^{43}$ an increased risk of hospitalisation due to musculoskeletal disorders and an increased rate of musculoskeletal sickness were reported to be associated with a lack of job control. In other studies, ${ }^{44}$ poor job content and low workplace social support were also shown to be risk factors for back pain. Thirdly, in our study, workplace co-worker support was noted to be significantly associated with chronic LBP in the univariate analysis but this association did not remain in the multivariate logistic regression analysis, probably because the ambulance workers as a group, worked collaboratively, to some extent, and the factor of co-worker support was not as significantly important as other psychological factors. Emergency ambulance nursing work not only requires high-intensity physical activity, but also demands professional skills and rapid responses in emergencies, which affect individuals' social psychology. Therefore, negative psychosocial work factors also need to be decreased to an acceptable level to control chronic LBP among ambulance nurses.

We also found that age, sex, BMI and work shift (shift work vs day work) were associated with chronic LBP. Another cross-sectional study ${ }^{45}$ of 1203 Iranian petrochemical employees also reported that musculoskeletal disorders were statistically more prevalent in shift workers than in day workers. In a prospective study ${ }^{46}$ of nurses' aides, LBP-related sick leaves were revealed to be correlated with working night shifts. Regarding the many risk factors of chronic LBP among ambulance nurses, one simple intervention measure alone may not be adequate. ${ }^{47}$ To achieve the aim of decreasing chronic LBP in ambulance nurses, multi-component comprehensive measures, including ergonomic and psychosocial intervention measures, might be considered in the future.

To our knowledge, this is the first large-scale survey aimed at exploring the LBP prevalence among ambulance workers and the risk factors for chronic LBP among 
ambulance nurses in China. The ambulance workers participating in the study were randomly selected in Shandong, China, and the response rate of $90.8 \%$ was acceptable. The limitations of our study included the use of self-reported measures and retrospective questionnaires. Therefore, it is inevitable to suffer from measurement bias. The cross-sectional design of the study precluded causal conclusions, and a prospective cohort study might be needed in the future. Some of the 158 subjects who failed to participate in the study might suffer from LBP, and the subjects who had left their ambulance position due to serious LBP were not included in the study. Therefore, the prevalence of LBP and the extent of its risk factors might be underestimated accordingly.

\section{CONCLUSIONS}

This study suggests a relatively higher prevalence of LBP among ambulance nurses than ambulance doctors and drivers. Psychosocial factors, such as occupational stress and psychological fatigue, and ergonomic factors, such as the frequent bending of the trunk and heavy or awkward lifting, played important roles in the development of chronic LBP. Comprehensive intervention measures, including ergonomic and occupational health intervention measures, might be suggested for LBP prevention.

Contributors HD designed the study, participated in the data collection and drafted and revised the manuscript. QZ participated in the design of the work, data collection, data analysis, interpretation of findings and revising the manuscript. CZ and GL contributed to data collection, interpretation of findings and revisions. All authors contributed to the paper revising and final approval of the version to be published.

Funding The authors have not declared a specific grant for this research from any funding agency in the public, commercial or not-for-profit sectors.

Competing interests None declared.

Patient consent for publication Not required.

Ethics approval The study was approved by the Ethics Committee of Shouguang People's Hospital (2016SD02011).

Provenance and peer review Not commissioned; externally peer reviewed.

Data availability statement Data are available upon reasonable request.

Open access This is an open access article distributed in accordance with the Creative Commons Attribution Non Commercial (CC BY-NC 4.0) license, which permits others to distribute, remix, adapt, build upon this work non-commercially, and license their derivative works on different terms, provided the original work is properly cited, appropriate credit is given, any changes made indicated, and the use is non-commercial. See: http://creativecommons.org/licenses/by-nc/4.0/.

\section{REFERENCES}

1. Sterud T, Ekeberg Øivind, Hem E. Health status in the ambulance services: a systematic review. BMC Health Serv Res 2006;6:82.

2. Broniecki M, Esterman A, May E, et al. Musculoskeletal disorder prevalence and risk factors in ambulance officers. J Back Musculoskelet Rehabil 2010;23:165-74.

3. Sterud T, Hem E, Ekeberg O, Ekeberg Øivind, et al. Health problems and help-seeking in a nationwide sample of operational Norwegian ambulance personnel. BMC Public Health 2008;8:3.

4. Xia T, Collie A. Work-Related injury and illness in the Victorian healthcare sector: a retrospective analysis of workers. Aust. Health Review 2018.

5. Hansen CD, Rasmussen K, Kyed M, et al. Physical and psychosocial work environment factors and their association with health outcomes in Danish ambulance personnel - a cross-sectional study. BMC Public Health 2012;12:534.

6. Roberts $\mathrm{MH}$, Sim MR, Black O, et al. Occupational injury risk among ambulance officers and paramedics compared with other healthcare workers in Victoria, Australia: analysis of workers' compensation claims from 2003 to 2012. Occup Environ Med 2015;72:489-95.

7. McDonald M, DiBonaventura MdaCosta, Ullman S. Musculoskeletal pain in the workforce: the effects of back, arthritis, and fibromyalgia pain on quality of life and work productivity. J Occup Environ Med 2011;53:765-70.

8. Hignett S, Griffiths P, Murdey ID, et al. Assessing management of musculoskeletal disorders in the ambulance service. Occup Med 2007;57:270-6.

9. Shiri R, Falah-Hassani K, Heliövaara M, et al. Risk factors for low back pain: a Population-Based longitudinal study. Arthritis Care Res 2019;71:290-9.

10. Stanislawska I, Mincewicz M, Cabak A, et al. Epidemiological aspects of low back pain. Adv Exp Med Biol 2019.

11. Vlaeyen JWS, Maher CG, Wiech K, et al. Low back pain. Nat Rev Dis Primers 2018;4.

12. da Costa BR, Vieira ER. Risk factors for work-related musculoskeletal disorders: a systematic review of recent longitudinal studies. Am J Ind Med 2010;53:285-323.

13. Ghaffari M, Alipour A, Farshad AA, et al. Effect of psychosocial factors on low back pain in industrial workers. Occup Med 2008;58:341-7.

14. Coskun Cenk S. An analysis of the exposure to violence and burnout levels of ambulance staff. Turk J Emerg Med 2019;19:21-5.

15. Durand A-C, Bompard C, Sportiello J, et al. Stress and burnout among professionals working in the emergency department in a French university hospital: prevalence and associated factors. Work 2019;63:57-67.

16. Gorman VL-A. Future emergency nursing workforce: what the evidence is telling us. J Emerg Nurs 2019;45:132-6.

17. Maguire BJ. Violence against ambulance personnel: a retrospective cohort study of national data from safe work Australia. Public Health Res Pract 2018;28(1.

18. Maguire BJ, O'Meara P, O'Neill BJ, et al. Violence against emergency medical services personnel: a systematic review of the literature. $\mathrm{Am}$ $J$ Ind Med 2018;61:167-80.

19. Kuorinka I, Jonsson B, Kilbom A, et al. Standardised Nordic questionnaires for the analysis of musculoskeletal symptoms. Appl Ergon 1987;18:233-7.

20. Hildebrandt VH, Bongers PM, van Dijk FJ, et al. Dutch musculoskeletal questionnaire: description and basic qualities. Ergonomics 2001;44:1038-55.

21. Li J, Yang W, Liu P, et al. Psychometric evaluation of the Chinese (mainland) version of job content questionnaire: a study in university hospitals. Ind Health 2004;42:260-7.

22. van Tulder M, Becker A, Bekkering T, et al. Chapter 3. European guidelines for the management of acute nonspecific low back pain in primary care. Eur Spine J 2006;15 Suppl 2:s169-91.

23. Yang L, Hildebrand V, Yu S, et al. The introduction of a musculoskeletal disorders questionnaire-the questionnaire attached. Industrial health and occupational diseases 2009;1:25-31.

24. Du W-wei, Wang S, Wang J-xin, et al. [The assessment of reliability and validity of musculoskeletal questionnaire]. Zhonghua Lao Dong Wei Sheng Zhi Ye Bing Za Zhi 2012;30:335-8.

25. Yu S, Lu M-L, Gu G, et al. Musculoskeletal symptoms and associated risk factors in a large sample of Chinese workers in Henan Province of China. Am J Ind Med 2012;55:281-93.

26. Alexopoulos EC, Burdorf A, Kalokerinou A. A comparative analysis on musculoskeletal disorders between Greek and Dutch nursing personnel. Int Arch Occup Environ Health 2006;79:82-8.

27. Sharma S, Shrestha N, Jensen MP. Pain-Related factors associated with lost work days in nurses with low back pain: a cross-sectional study. Scand J Pain 2016;11:27-33.

28. Feng $\mathrm{C}-\mathrm{K}$, Chen M-L, Mao I-F. Prevalence of and risk factors for different measures of low back pain among female nursing aides in Taiwanese nursing homes. BMC Musculoskelet Disord 2007;8:52.

29. Coluci MZO, Alexandrea NMC. Job factors related to musculoskeletal symptoms among nursing personnel--a review. Work 2012;41 Suppl 1(Suppl 1):2516-20.

30. Sadeghian F, Hosseinzadeh S, Aliyari R. Do psychological factors increase the risk for low back pain among nurses? A comparing according to cross-sectional and prospective analysis. Saf Health Work 2014;5:13-16.

31. Scott NA, Moga C, Harstall C. Managing low back pain in the primary care setting: the know-do gap. Pain Res Manag 2010;15:392-400.

32. European guidelines for the management of low back pain. Acta Orthop Scand 2002;73:20-5. 
33. Jäger M, Jordan C, Theilmeier A, et al. Lumbar-load analysis of manual patient-handling activities for biomechanical overload prevention among healthcare workers. Ann Occup Hyg 2013;57:528-44.

34. Sterud T, Tynes T. Work-Related psychosocial and mechanical risk factors for low back pain: a 3-year follow-up study of the general working population in Norway. Occup Environ Med 2013;70:296-302.

35. Hodder JN, MacKinnon SN, Ralhan A, et al. Effects of training and experience on patient transfer biomechanics. Int $J$ Ind Ergon 2010;40:282-8.

36. Huang GD, Feuerstein M, Sauter SL. Occupational stress and workrelated upper extremity disorders: concepts and models. Am J Ind Med 2002;41:298-314.

37. Jones AYM, Lee RYW. Cardiopulmonary resuscitation and back injury in ambulance officers. Int Arch Occup Environ Health 2005;78:332-6.

38. From the Centers for Disease Control and Prevention. Ambulance crash-related injuries among Emergency Medical Services workers-United States, 1991-2002. JAMA 2003;289:1628-9.

39. Gander P, O'Keeffe K, Santos-Fernandez E, et al. Fatigue and nurses' work patterns: an online questionnaire survey. Int J Nurs Stud 2019;98:67-74.
40. Hatch DJ, Freude G, Martus P, et al. Age, burnout and physical and psychological work ability among nurses. Occup Med 2018;68:246-54.

41. Barker LM, Nussbaum MA. The effects of fatigue on performance in simulated nursing work. Ergonomics 2011;54:815-29.

42. Silva TPDda, Araújo WNde, Stival MM, et al. Musculoskeletal discomfort, work ability and fatigue in nursing professionals working in a hospital environment. Rev Esc Enferm USP 2018;52:e03332.

43. Yip VYB. New low back pain in nurses: work activities, work stress and sedentary lifestyle. J Adv Nurs 2004;46:430-40.

44. Louw QA, Morris LD, Grimmer-Somers K. The prevalence of low back pain in Africa: a systematic review. BMC Musculoskelet Disord 2007;8:105.

45. Choobineh A, Soltanzadeh A, Tabatabaee $H$, et al. Health effects associated with shift work in 12-hour shift schedule among Iranian petrochemical employees. Int J Occup Saf Ergon 2012;18:419-27.

46. Eriksen W, Bruusgaard D, Knardahl S. Work factors as predictors of intense or disabling low back pain; a prospective study of nurses aides. Occup Environ Med 2004;61:398-404.

47. Tullar JM, Brewer S, Amick BC, et al. Occupational safety and health interventions to reduce musculoskeletal symptoms in the health care sector. J Occup Rehabil 2010;20:199-219. 